\title{
DECENTRALIZATION AND FOOTBALL*
}

\author{
Ignacio Lago \\ Universitat Pompeu Fabra and Governance and Economics research Network (GEN) \\ Department of Political and Social Sciences \\ Universitat Pompeu Fabra \\ Ramon Trias Fargas 25-27 \\ 08005 Barcelona, Spain \\ ignacio.lago@upf.edu \\ Carlos Lago-Peñas \\ University of Vigo and Governance and Economics research Network (GEN) \\ Faculty of Education and Sport Sciences \\ University of Vigo \\ Campus Universitario s/n \\ 36005 Pontevedra, Spain \\ clagop@uvigo.es \\ Santiago Lago-Peñas \\ Governance and Economics research Network (GEN) and University of Vigo \\ Faculty of Business \\ University of Vigo \\ Campus Universitario s/n \\ 32004 Ourense, Spain \\ slagop@uvigo.es
}

\begin{abstract}
We argue that decentralization of economic and political power makes a substantial difference in football. We demonstrate, with analyses of 35 European democratic countries over the period 1950-2010, that regional autonomy boosts the competition among clubs from different regions and results in a greater competitive balance of domestic football leagues. This first-moment effect creates an advantage for clubs from decentralized countries in international competitions. Evidence from the first 18 editions of the UEFA Champions League shows that clubs from decentralized countries have a greater chance of winning, or at least playing in the final, than those from centralized countries.
\end{abstract}

Key words: Competitive balance, Decentralization, Football, Identities.

*We thank Ángel Barajas for his helpful comments and Alejandro Domínguez and Jesyca Salgado for superb research assistance. The authors acknowledge financial support from the Spanish Minister of Economy and Competitiveness (CSO2017-85024C2-1-P and CSO2017-85024-C2-2-P). The datasets can be found at http://slagop.webs.uvigo.es/ 


\section{Introduction}

Despite the fact that the Premier League is by far the European's richest football league (Deloitte Football Money League, 1997-2017), only 4 of the 25 Union of European Football Associations (UEFA) Champions League have been won by English football clubs. In terms of individual clubs, according again to the Money Leagues, in the last 20 seasons Manchester United's revenue has been greater than Milan's and in 19 out of 20 seasons greater than Bayer Munich's. However, the three clubs have won the same number of UEFA Champions Leagues (2) and Manchester United has played fewer finals than Bayer Munich (4 versus 5).

In this paper we argue that, apart from money and of course chance, the degree of countries’ political and economic decentralization positively increases the likelihood of winning football international trophies. Our argument is that the authority exercised by regional governments over those who live in the regions (i.e., Self-rule in Elazar's terms, 1987) has both first- and second-moment effects. The first-moment effect concerns the competitive balance of domestic football leagues. We rely on longitudinal data from 35 European democratic countries in the period 1950-2010 to show that decentralization: a) boosts the competition among clubs from different regions, and b) results in a greater competitive balance of domestic football leagues. Regional autonomy exacerbates the identification with football clubs and rivalries between football clubs, allows the spread of economic resources outside the capital city and increases the support received by football clubs from regional governments and financial institutions.

The second-moment effect refers to the competitive advantage in international competitions of clubs from domestic leagues with a greater competitive balance due to the decentralization of power. The evidence from the first 18 editions of the UEFA Champions League leads us to conclude that clubs from decentralized countries have a greater chance of winning, or at least playing the final, than clubs from centralized countries. 


\section{Arguments}

Decentralization of political and economic power-the devolution of autonomous political and fiscal power to subnational officials as defined by O’Neill (2003) — has been a worldwide trend in the last decades. According to the World Bank (2000, p. 107), at the beginning of the $21^{\text {st }}$ century, “some 95 percent of democracies now have elected subnational governments, and countries everywhere - large and small, rich and poor - are devolving political, fiscal, and administrative powers to subnational tiers of government.” However, differences across countries are huge. In the sample of 29 countries whose clubs have played at least once the group stage of UEFA Champions League and included in data compiled by Hoogue et al. (2016), there are several completely centralized countries (e.g., Iceland or Luxembourg), while Germany and Spain are the two most decentralized countries in Europe (and in the world). The score for United Kingdom is close to the average.

According to the well-established theory of fiscal federalism, a decentralized government structure involves an increased citizen welfare and efficiency in the allocation of resources (Martínez-Vázquez et al. 2017). Proximity makes information flow more easily and gives more flexibility to match citizens' needs and preferences. More important for our argument it is that decentralization reduces the concentration of resources in the national capital and opens the door to interregional competition in public choices.

Existing research about the demand for football shows that it provides "people with common interests, loyalties and enthusiasm, thus serving as a way to unite diverse groups within a community against outsiders” (Chen 2007, p. 38). Fan interest for football is mainly a matter of identification with a club, grounded on a geographic or emotional connection and with a strong basis in the self-identity of the fan (Borland and Mcdonald, 2003). For example, De Ruyter and Wetzels (2000) found that supporters buying shares from their clubs to provide assistance in times of financial need were not motivated by an economic return but rather by the social norm of reciprocity. Thus, professional football clubs serve as central markers of identity in geographical regions or local communities (Storm and Nielsen 2012).

Our point is that regional autonomy exacerbates the identification with football clubs and rivalries between football clubs from different regions. This leads to a greater competitive balance in domestic football leagues in decentralized countries than in centralized countries. The enmity between Northern and Southern Italy or between Catalonia and Madrid in Spain are enlightening examples. Individual-level data from Spain, for example, strongly support this relationship between regions and football 
clubs. According to a survey conducted on a representative sample of 1,200 individuals in $1999,{ }^{1}$ for most of the Catalans (53 percent), the Barcelona Football Club is identified with Catalonia, while only 21 percent believed it is mainly a football club. ${ }^{2}$

Two institutional and sociological mechanisms are behind the impact of decentralization on football. First, regional governments are closely involved in supporting football clubs given their cultural and political significance (Szymanski 2015). In Putnam`s (1993) classical study of democratic institutional performance in Italy, membership in sports clubs is a key indicator of civic sociability and performance of a regional government: Most of local associations in Italy are sports clubs. Indeed, football clubs were the hallmarks of a successful region in Italy (Putnam 1995).

A clear indicator of the active role of regional governments supporting football clubs are the soft budget constraints within professional football in which clubs operate (Storm and Nielsen 2012). When a club is close to going bankrupt, usually some supporting organization steps in financially to rescue it. According to Andreff (2015), European football exhibits more clubs in the red than in the black. As Storm and Nielsen put it (2012, p. 195), "it is specific for professional football clubs that this willingness [to bail them out or support them at times of financial trouble] originate from the way in which these clubs serve as central markers of identity in geographical regions or local communities to which the stakeholders are socially and emotionally attached to such a degree that the environment supports their survival.” In particular, football clubs are heavily backed by their respective regions, that is, governments and financial institutions (Barajas and Rodriguez 2010). At the same time, decentralization allows the spread of economic resources outside the capital city and increases the competition between regions. For instance, from 1950 to 2010, 5 football leagues in Switzerland and 0 in Germany, on the one hand, and 30 in Iceland and 17 in Luxembourg, on the other, have been won by clubs from the capital city. Our expectation is that the greater the powers of a regional government and the stronger the identification with the football club, the more incentives regional governments face to support it.

Second, we hypothesize that identifications with football clubs should get stronger as regional policies become more important for individuals' well-being. Unfortunately, we have not come across any study that measures identifications with football clubs in centralized and decentralized countries or in a given country across a

${ }_{1}^{1}$ http://ceo.gencat.cat/ceop/AppJava/pages/estudis/registrats/fitxa/fitxaEstudi.html?colId=43\&lastTitle=La +imagen+de+Catalunya+en+Espa\%F1a.+Gener+1999. See also Llopis Goig (2006).

${ }^{2}$ The exact wording of the question is a s follows: "When we talk about the Barcelona Football Club, what do you identify it with firstly? With a football club, with the city of Barcelona, with Catalonia, DK/NA" 
decentralization process. However, there is strong evidence supporting that regional identification increase with decentralization (Martínez-Herrera, 2002) and probably identifications with football clubs also do. This argument is in line with the conventional wisdom about how decentralization ought to inspire the creation and growth of regional parties. As explained and shown by Lublin (2012, 2014), greater self-rule may well increase incentives toward regional party formation in regional elections as autonomy makes control of regional governments more attractive. A similar point is made by Brancati (2008) when she argues that decentralization encourages regional party growth as it provides opportunities to accrue power and resources at the regional level. If fan interest in clubs from the regions increases as a consequence of decentralization, clubs' economic resources should also increase and regional governments and financial institutions will face stronger incentives to support football clubs.

The second point in our argument is that decentralization does not only affect domestic leagues, but also football clubs' chances of winning international trophies. The greater competitive balance of domestic football leagues in decentralized countries should generate a competitive advantage for their clubs over clubs from centralized countries. The more competitive domestic football leagues are, the greater the quality of the clubs. Therefore, all else equal, football clubs from decentralized countries should have a greater chance of winning international trophies.

The foregoing discussion generates two hypotheses:

Hypothesis 1. The greater the decentralization of economic and political power, the greater the competitive balance of domestic football leagues.

Hypothesis 2. Due to the advantage generated by the greater competitive balance in their domestic football leagues, clubs from decentralized countries have a higher chance of winning international trophies than clubs from centralized countries. 


\section{Data and methods}

The empirical analysis proceeded in two steps. The first step showed that decentralization increases the competitive balance of domestic football leagues in Europe; the second step examined the extent to which the chance of winning the UEFA Champions League, or at least playing in the final, is affected by the degree of decentralization of political and economic power.

The effect of decentralization on the competitive balance of domestic football leagues is examined through a pooled cross-sectional time-series analysis in 35 European countries from 1950 to 2010. The sample includes all European countries for which comparable data on the level of democracy and decentralization and information about football domestic leagues are available. As the popularity of football differs greatly across regions, the focus on European countries allows us to control for popularity of the sport. Our assumption is that the popularity of football is largely similar across countries and over time. We have selected the $1950-2010$ period due to the availability of data for Self-rule in the dataset generated by Hoogue et al. (2016). Finally, given that the competitive balance of domestic football leagues is affected by the type of political regime (Lago et al. 2016), only democracies are included in the sample. For those countries which have experienced a transition to democracy after 1950, we have only selected those years in which the country is a democracy. Countries are defined as democratic according to Cheibub et al.'s rules (2010). ${ }^{3}$ See the Appendix for a description of the sample.

As decentralization (i.e., Self-rule) changes over time, the competitive balance of domestic football leagues in our sample of countries has been measured for decades. There is no unique way to measure dominance in sports league (see Szymanski 2015 or Humphreys and Watanabe, 2012). The measure used here is based on the Gini coefficient per decade and captures at the same time the number of leagues won by each club and the number of different clubs winning leagues. A Gini coefficient of 0 means that 10 different clubs have won the leagues in the 10 years (i.e., the maximum competitive balance), while a Gini coefficient of 1 means that the 10 leagues have been won by the same club (i.e., the minimum competitive balance). Some of the countries in the sample transitioned to democracy after 1950. Those decades in which the transition took place are only included in the analyses if there is a minimum of 5 leagues played

\footnotetext{
${ }^{3} \mathrm{~A}$ regime is considered a democracy if the executive and the legislature are directly or indirectly elected by popular vote, when multiple parties are allowed, when there is de facto existence of multiple parties beyond the regime, when there are multiple parties within the legislature, and when there has been no consolidation of incumbent advantage (e.g. unconstitutional closing of the lower house or extension of incumbent's term by postponing of subsequent elections). Transition years are coded as the regime that emerges in that year.
} 
under democracy. ${ }^{4}$ As can be seen in Table 1, the average Gini coefficient is 0.81 and the standard deviation is 0.12 . It goes from 0.4 in Germany and 0.47 in Finland in the 1950s to 0.99 in Greece in the 2000s and Norway in the 1990s and 1 in Latvia in the 1990s.

The key independent variable, Self-rule, captures the degree of decentralization in the countries. More specifically, it measures the authority exercised by a regional government over those who live in the region. ${ }^{5}$ We have calculated the average per decades in congruence with the definition of the dependent variable. The source is Hoogue et al. (2016).

We also include some control variables that hamper or make easier having dominant clubs in domestic football leagues. They have been operationalized as follows:

-Country Size: As country's social heterogeneity increases as it becomes larger, the larger the country, the more competitive clubs should be. The size of the country has been measured in thousands of $\mathrm{km}^{2}$. The variable is time-invariant. The expectation is that the larger the country, the greater the competitive balance of domestic leagues. ${ }^{6}$

-Per Capita Income (in constant thousands of dollars, Chain Index, expressed in international prices, base 2005, taken from the Penn World Tables, PWT 7.1) is expected to enter negatively in the model. Information is not available for Germany in the 1950s and 1960s and for Malta in the 1960s. It has been measured as the average per decade. As income increases, both the resources available for being invested in football clubs and fan interest increase and this should go in the direction of competitive balance.

- Clubs: the number of clubs playing the domestic league has been taken from the respective websites of football national associations or other electronic sources. It has been measured as the average per decade in every country of the sample. The most important change took place in Germany: before 1964, the number of clubs playing the league was 9; after 1963, when the Bundesliga was formed, 18. The variable should decrease the competitive balance of domestic leagues. When new clubs enter the league,

\footnotetext{
${ }^{4}$ The results are virtually the same if decades with less than 10 years when the country transitioned to democracy are dropped.

${ }^{5}$ The Regional Authority Index is a measure of the authority of regional governments across ten dimensions: institutional depth, policy scope, fiscal autonomy, borrowing autonomy, representation, law making, executive control, fiscal control, borrowing control, and constitutional reform. These ten dimensions constitute two domains of authority: Self-rule, or the authority a regional government exerts within its territory; and Shared-rule, or the authority a regional government or its representatives exerts in the country as a whole. Country scores aggregate scores for each regional tier and individual regional governments in a country (Hoogue et al. 2016).

${ }^{6}$ The results do not change appreciably when the geographical area of countries is replaced with (the log of) their population (in thousands).
} 
they are normally weaker than established clubs and as a result our dependent variable, the Gini coefficient, rises.

- Ethnic Fragmentation: The existence of distinct ethnic groups in a country can encourage the creation of competitive clubs representing those groups. As Duke and Crolley (1996) argue, football may provide an important means of expressing latent nationalism with the gathering of large crowds in the stadium. The most commonly used measure of aggregate social heterogeneity is fractionalization, defined as the probability that two individuals selected at random from a country will be from different ethnic groups. The formula is as follows: $F R A C T_{j}=1-\sum_{i=1}^{N} s_{i j}^{2}$ where $s_{i j}$ is the proportion of group $i(i=1 \ldots N)$ in country $j$. The higher the value of FRACT, the higher fractionalization will be. The variable is time-invariant. The source is Alesina et al. (2003). ${ }^{7}$ The expectation is that fragmentation should increase the competitive balance of domestic leagues.

According to preliminary tests (not shown), both individual and period effects have to be included in the models. However, as the controls are totally or largely timeinvariant, there is a problem of multicollinearity between then and the individual fixed effects. To deal with this problem and check the robustness of our results, we have estimated two different specifications. In [1] we include the controls without the individual fixed effects; in [2] the controls are omitted and the individual fixed effects are added. In both models, Self-rule is retained. Standard residuals show that autocorrelation is not a serious concern. Finally, OLS standard errors are replaced with Cross-Section weights (PCSE) standard errors to control for heteroscedasticity:

$$
\begin{aligned}
& \operatorname{Gini}_{\mathrm{it}}=\lambda_{\mathrm{t}}+\beta_{0}+\beta_{1} \cdot \text { Selfrule }_{\mathrm{it}}+\beta_{2} \cdot \text { Size }_{\mathrm{it}}+\beta_{3} \cdot \text { Income }_{\mathrm{it}}+ \\
& +\beta_{4} \cdot \# \text { Club s }_{\mathrm{it}}+\beta_{5} \cdot \text { Ethnicfragmentation }_{\mathrm{it}}+\varepsilon_{\mathrm{it}} \\
& \operatorname{Gini}_{\mathrm{it}}=\alpha_{\mathrm{i}}+\lambda_{\mathrm{t}}+\beta_{0}+\beta_{1} \cdot \text { Selfrule }_{\mathrm{it}}+\varepsilon_{\mathrm{it}}
\end{aligned}
$$

The descriptive statistics of the variables in the two empirical analyses are displayed in Table 1.

\footnotetext{
7 Since Montenegro and Serbia are not included independently in Alesina et al.'s sample, we have calculated its fragmentation according to the 2003 census. We have attributed both to England the values for United Kingdom.
} 
Table 1: Descriptive statistics

\begin{tabular}{l|ccccc|ccccc}
\hline & \multicolumn{7}{|c|}{ Competitive balance of football domestic leagues } & \multicolumn{6}{c}{ Performance in the UEFA Champions League } \\
\hline Variable & Obs & Mean & Std. Dev. & Min. & Max. & Obs & Mean & Std. Dev. & Min. & Max. \\
\hline Gini coefficient & 142 & 0.81 & 0.12 & 0.4 & 1 & - & - & - & - & - \\
Self-rule & 142 & 8.24 & 7.46 & 0 & 25.95 & 254 & 13.18 & 6.92 & 0 & 24.99 \\
Size & 142 & 183.62 & 199.25 & 0.32 & 780.58 & - & - & - & - & - \\
Income & 139 & 19.12 & 10.93 & 2.88 & 72 & - & - & - & - & - \\
\# of Clubs & 142 & 14.60 & 3.58 & 8 & 20.2 & - & - & - & - & - \\
Ethnic fragmentation & 142 & 0.22 & 0.18 & 0.04 & 0.59 & - & - & - & - & - \\
Winner & - & - & - & - & - & 254 & 0.07 & 0.25 & 0 & 1 \\
Finalist & - & - & - & - & - & 254 & 0.12 & 0.33 & 0 & 1 \\
Revenue ranking & - & - & - & - & - & 254 & 0.63 & 1.27 & 0 & 5 \\
\hline
\end{tabular}

The second empirical analysis is focused on how countries, or more specifically clubs representing countries, do in the UEFA Champions League. We have selected the 18 editions of the UEFA Champions League held since the season 1992/93, when the straight knockout tournament open only to the champion club of each country was replaced with a group stage and multiple entrants from certain countries, until 2010, the last year in which Self-rule scores are available. The unit of analysis are countries in every edition of the UEFA Champions League. The number of observations is equal to the number of editions of the UEFA Champions League played by clubs from every country. As the format of the competition has slightly changed over time, we decided to focus on those clubs participating in the group stage in order to make a similar comparison in all the editions. This means that those countries with the weakest leagues are excluded from the analysis. We believe that this decision does not affect our results because, first, the range of all the dependent and independent variables is not limited and, second, the countries in the two extremes of the competitive balance of football domestic leagues (Germany and Finland versus Greece and Norway) are included in the sample.

We have two dependent variables. First is a dummy variable, Winner, coded 1 when a given country (i.e., any club from the country) won the corresponding edition of the UEFA Champions League, 0 otherwise. In order to minimize the random component of success, our second variable, Finalist, captures whether a given country (i.e., any club from the country) has played the final of the corresponding edition of the UEFA Champions League, 0 otherwise. In sum, when Winner is the dependent variable, there are 18 values equal to 1 ; when Finalist is the dependent variable, there are 33 
values equal to 1 (in the seasons 1999/2000, 2002/03 and 2007/08 two clubs from the same country played the final). ${ }^{8}$

The key independent variable is Self-rule again. The expected effect of the variable is positive: the more decentralized a country, the more likely that a club from the country wins the UEFA Champions League or at least plays the final. We control for clubs’ earnings from matchday revenue, broadcast rights and commercial sources in the previous season. The information comes from the Deloitte Football Money League reports. Unfortunately, the Money League only provides data on the richest clubs, and its first edition was produced for the 1996/97 season. We have created a variable, Revenue ranking, capturing the number of clubs in every country in each season appearing in the top 10 clubs by revenue in the previous season. As can be seen in Figure 1, with some slight changes over time, all the top 10 clubs belong to four different countries, England, Italy, Spain and Germany. Since 2002, England is the country with the highest number of clubs in the top 10. The value of Revenue ranking for all the remaining countries is 0. For the seasons before 2002, we have imputed to the corresponding country its value in the 1997/98 season. Given the stable ranking over time, we think that this imputation makes sense.

The dependent variables are dichotomous and for this reason logistic regressions have been run with clusters for countries to account for the non-independence in the data structure.

\footnotetext{
${ }^{8}$ In the seasons 1999/2000, 2002/03 and 2007/08 the finals were Real Madrid vs Valencia (Spain), Milan vs Juventus (Italy) and Manchester United vs Chelsea (England), respectively.
} 
Figure 1: Number of clubs per country in the top 10 clubs by revenue

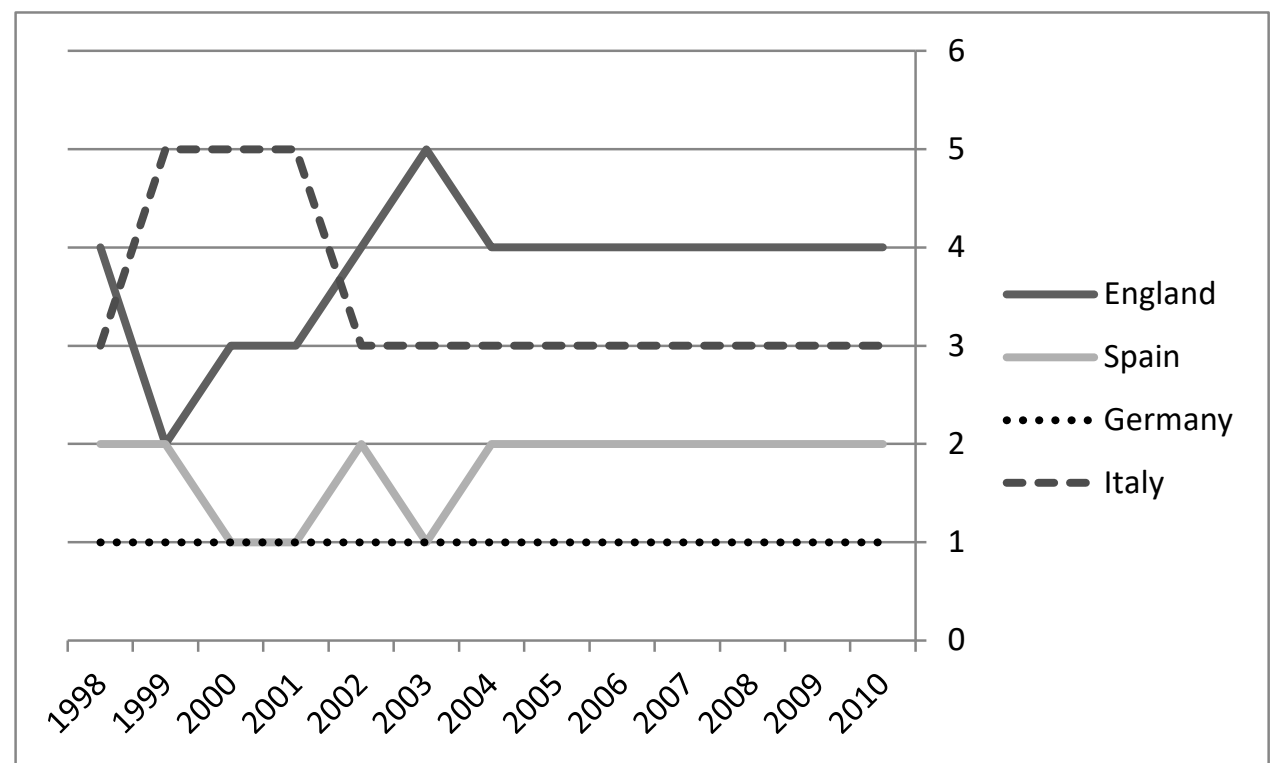

Source: Deloitte Football Money League.

\section{Results}

Decentralization and the competitive balance of domestic football leagues

The loess curve in Figure 2 shows that there is a negative correlation between the competitive balance of domestic football leagues in Europe, captured with the Gini coefficient, and the degree of decentralization, measured with Self-rule. As expected, the more decentralized a country is, the greater the competitive balance.

Figure 2: Decentralization and the competitive balance of domestic football leagues in Europe

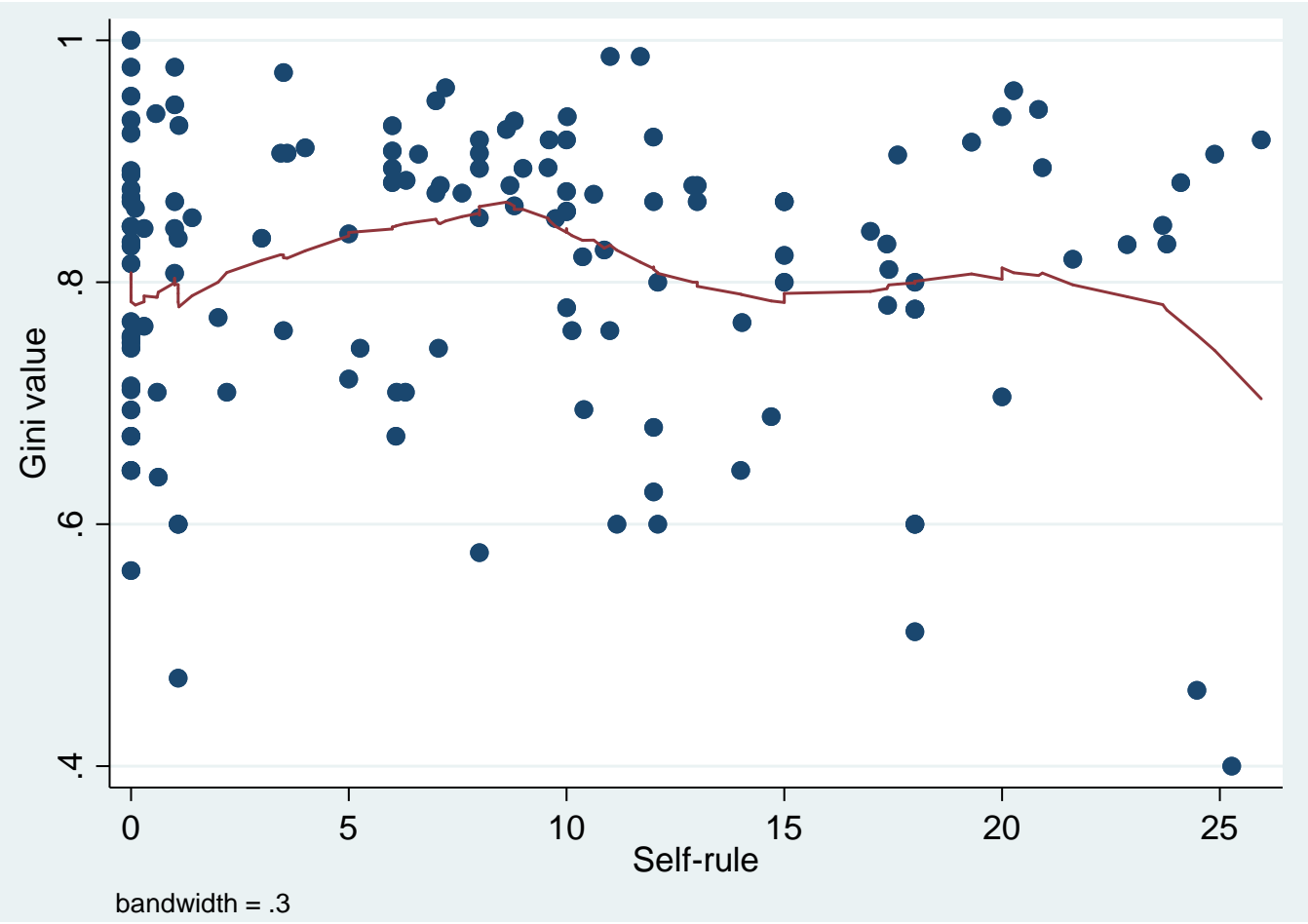


The results of the specifications [1] and [2] are displayed in Table $2 .{ }^{9}$ In the two models, the greater the decentralization in a country, the greater the competitive balance of domestic football leagues. Self-rule is statistically significant at the 0.05 percent level in both models and has the expected negative sign. The coefficient on Self-rule, however, is about three times larger in the model with individual and period effects than in the model with only period effects. An increase of ten points in Self-rule decreases the Gini coefficient in 0.073 in the former and 0.027 in the latter. The only statistically significant control is the number of Clubs (with the expected sign). Finally, the fit of the model with individual and period effects is the highest.

Table 2: The determinants of competitive balance in domestic football leagues

\begin{tabular}{l|c|c}
\hline & Model 1 & Model 2 \\
\hline Self-rule & $-0.0027^{* *}$ & $-0.0073^{* *}$ \\
Size & $(0.0013)$ & $(0.0038)$ \\
& -0.000054 & \\
Income & $(0.000047)$ & \\
& -0.00010 & \\
\# of Clubs & $(0.00069)$ & \\
& $0.019 * * *$ & \\
Ethnic fragmentation & $(0.0032)$ & \\
R & 0.073 & 0.518 \\
N (35 countries from 1950 to 2010) & $(0.043)$ & 142 \\
Fixed effects specification & 0.355 & Both individual and period effects \\
\hline
\end{tabular}

Cross-Section weights (PCSE) standard errors in parenthesis.

$* * * \mathrm{p}<0.01 ;{ }^{* *} \mathrm{p}<0.05$.

\footnotetext{
${ }^{9}$ The number of observations drops in the first model because the information about income per capital is not available for all countries in the sample.
} 
Decentralization and performance in the UEFA Champions League

The first piece of evidence supporting that decentralization creates a competitive advantage for clubs in the UEFA Champions League is shown in Figure 3. As can be seen, there are substantial differences in Self-rule between those countries with and without clubs winning at least one UEFA Champions League in the 1992/93-2009/10 period. The mean of Self-rule in the first group of countries (7) is 15.62 and in the second group of countries (22) is 9.07. The difference is statistically significant at the 0.05 percent level $(\mathrm{t}=2.23) .^{10}$

Figure 3: Decentralization in countries winning and not winning the UEFA Champions League

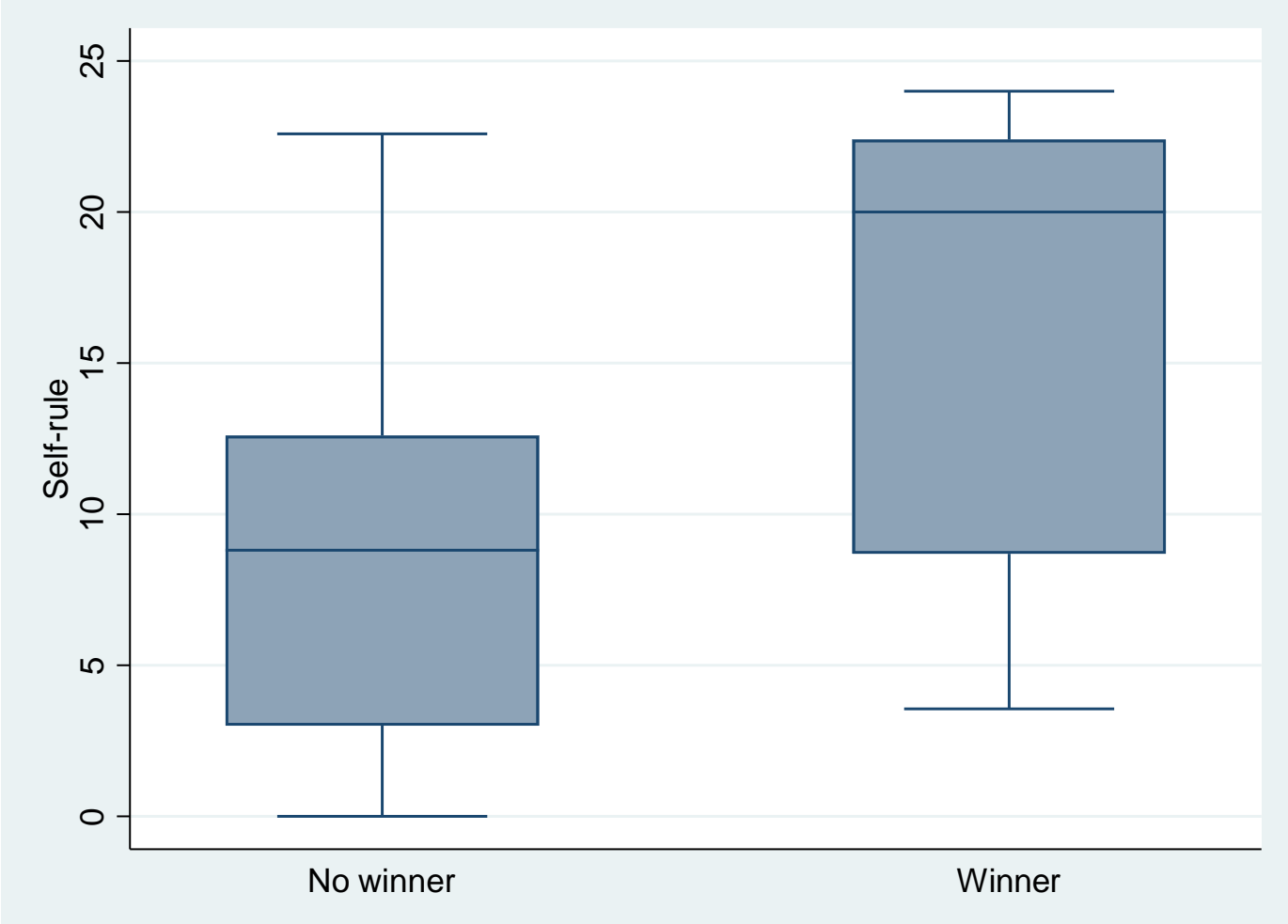

The results of the regression models are presented in Table 3. As expected, the four models show that the greater the decentralization in a country, the greater the probability that a club from the country wins or plays the final of the UEFA Champions League. Both when the dependent variable is Winner and Finalist, Self-rule is statistically significant at the 0.05 percent level or better. Interestingly, both the coefficient and the statistical significance of Self-rule increase when controlling for clubs’ earnings. Revenue ranking positively affects the chances of winning or playing the final of the UEFA Champions League and is statistically significant at the 0.01

\footnotetext{
${ }^{10}$ The figure is exactly the same when comparing countries playing and not playing the final as there are no countries with clubs playing the final and not winning.
} 
percent level when explaining the two dependent variables. The fit of the models substantially increases when the control is added.

Table 3: The determinants of success in the UEFA Champions League

\begin{tabular}{l|cc|cc}
\hline & \multicolumn{2}{|c|}{ Winner } & \multicolumn{2}{c}{ Finalist } \\
\hline Self-rule & $0.117^{* *}$ & $0.084^{* * *}$ & $0.129 * * *$ & $0.097 * * *$ \\
& $(0.048)$ & $(0.027)$ & $(0.050)$ & $(0.028)$ \\
Revenue ranking & & $0.502^{* * *}$ & & $0.680^{* * *}$ \\
& & $(0.123)$ & & $(0.142)$ \\
Constant & $-4.387 * * *$ & $-4.475^{* * *}$ & $-0.393^{* * *}$ & $-4.249 * * *$ \\
& $(0.911)$ & $(0.573)$ & $(0.996)$ & $(0.671)$ \\
Pseudo R ${ }^{2}$ & 0.076 & 0.150 & 0.102 & 0.237 \\
N & 254 & 254 & 254 & 254 \\
\# clusters & 29 & 29 & 29 & 29 \\
\hline
\end{tabular}

Robust Standard errors in parentheses.

$* * * \mathrm{p}<0.01 ;{ }^{* *} \mathrm{p}<0.05$.

The effect of Self-rule in the two models with the control is shown in Figure 4. In totally centralized countries (i.e., the value of Self-rule is 0), the probability of winning the UEFA Champions League is 2 percent. As decentralization increases, this probability increases in a quadratic way. When Self-rule is 25, the highest value in our sample (i.e., in Germany), the probability of winning the UEFA Champions League is 13 percent. The gap is greater for the second dependent variable. The probability of playing the final is 4 percent for clubs representing totally centralized countries and 23 percent for the most decentralized country in the sample. 
Figure 4: The impact of decentralization on the probability of winning the UEFA Champions League or playing the final
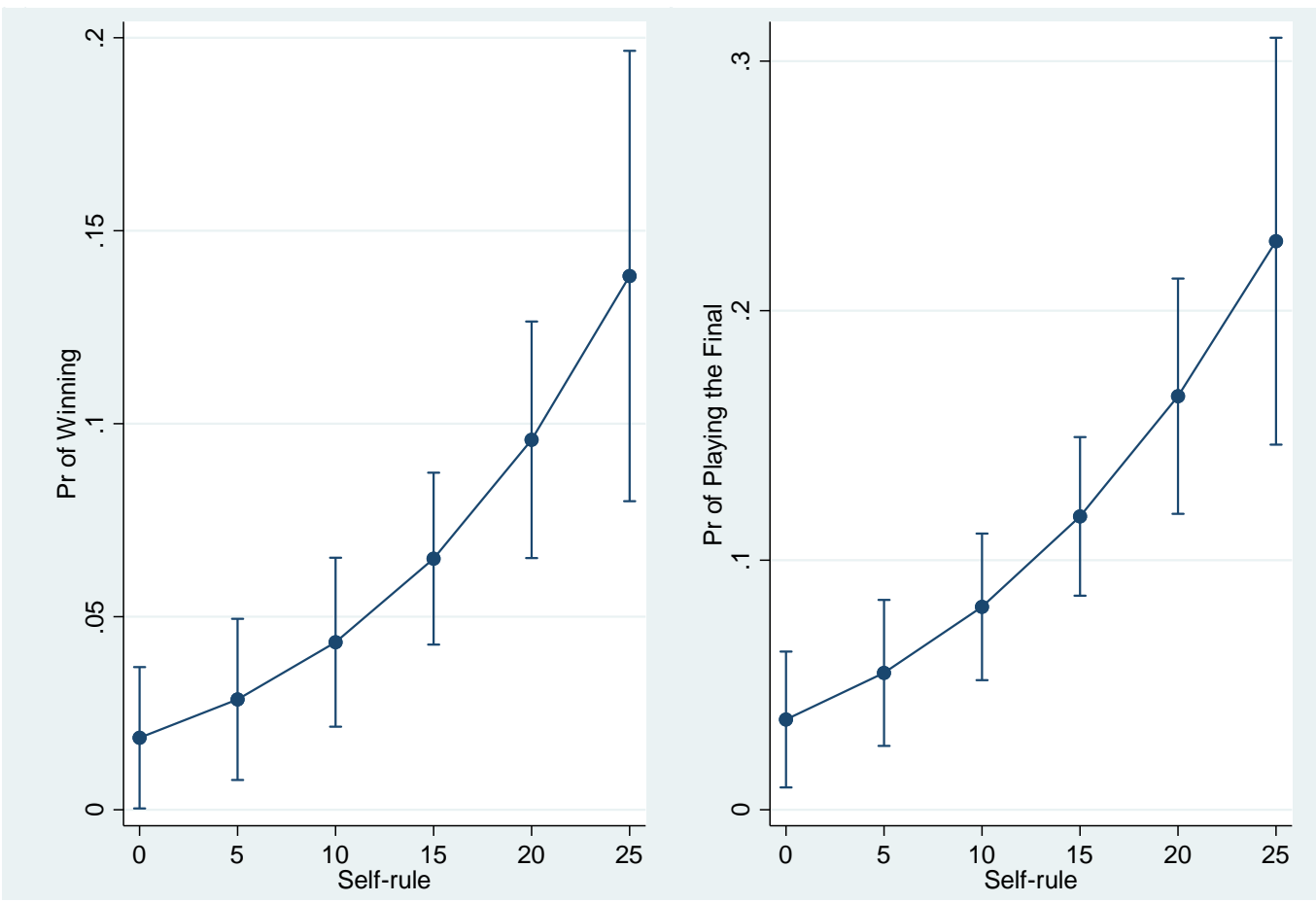

We have explored the robustness of the impact of decentralization in four additional ways. The first way is excluding those years in which the Deloitte Football Money League report is not available (i.e., from 1993 to 1997). The results remain qualitatively the same and provide again compelling evidence in favor of the decentralization hypothesis. Second, the annual revenue rankings from Deloitte have been replaced with the average from the whole period in order to reduce the potential problem of endogeneity between success in the UEFA Champions League and revenue. Self-rule is statistically significant at the 0.01 percent level in the two models and the fit is even better than when using the annual revenue rankings. Third, the annual revenue rankings from Deloitte have been replaced with the list of the 20 richest clubs in the world as ranked by Forbes magazine on their worth in United States dollars. As the list is only available from 2007 to 2016, we have attributed to the countries in our sample in all years the average from the period. Self-rule positively affects again the chances of winning or playing the final and is statistically significant at the 0.01 percent level. Due to the greater variability of the Forbes list than the Deloitte rankings, the fit of the models is better when using the former measure. The last robustness check is replacing Self-rule with the Regional Authority Index (RAI), which is the result of adding Self-rule and Shared-rule. The data come from Hoogue et al. (2016). The results do not change appreciably. ${ }^{11}$

${ }^{11}$ All the results are available upon request. 


\section{Conclusions}

We have argued here that the degree of political and economic decentralization has two important effects on domestic and international football leagues. The greater the authority exercised by regional governments over those who live in the regions (i.e., the greater Self-rule), the greater the competitive balance of domestic football leagues. Regional autonomy boosts the competition among clubs from different regions, increases fan interest, spreads economic resources outside the capital city and, finally, increases the support received by football clubs from regional governments and financial institutions.

This first-moment effect of decentralization creates an advantage for clubs from decentralized countries in international competitions. All else equal, clubs from the most decentralized country in our sample, Germany, have a much greater chance of winning UEFA Champions League—or at least playing the final—as much as 12 and 19 percent points, respectively, than clubs from the most centralized countries (Iceland or Luxembourg). 


\section{References}

Andreff, Wladimir (ed.). 2015. Disequilibrium Sports Economics. Competitive Imbalance and Budget Constraints. Cheltenham, UK and Northampton, MA, USA: Edward Elgar.

Borland, Jeffery and Robert Macdonald. 2003. "Demand for Sport.” Oxford Review of Economic Policy 19: 478-502.

Brancati, Dawn. 2008. “The Origins and Strengths of Regional Parties”. British Journal of Political Science 38: 135-159.

Cheibub, José Antonio, Jennifer Gandhi and James Raymond Vreeland. 2010. “Democracy and dictatorship revisited.” Public Choice 143: 67-101.

Chen, Jin-Long. 2007. Managerial factors affecting team identification (Ph.D. dissertation). The Florida State University, Florida.

Deloitte. 1997-2017. Football Money League. Manchester: Sports Business Group at Deloitte.

De Ruyter, Ko and Martin Wetzels. 2000. "With a little help from my fans: Extending models of pro-social behaviour to explain supporters' intentions to buy soccer club shares.” Journal of Economic Psychology 21: 387-409.

Duke, Vic and Liz Crolley. 1996. Football, nationality and the state. New York: Addison Wesley Longman.

Elazar, Daniel. 1987. Exploring federalism. Tuscaloosa, Alabama: The University of Alabama Press.

Hooghe, Liesbet, Gary Marks, Arjan H. Schakel, Sandi Chapman Osterkatz, Sara Niedzwiecki and Sarah Shair-Rosenfield. 2016. Measuring Regional Authority: A Postfunctionalist Theory of Governance, Volume I. Oxford: Oxford University Press.

Humphreys, Brad R. and Nicholas M. Watanabe. 2012. “Competitive Balance”. In The Oxford Handbook of Sports Economics, Volume I. Leo Kahane and Steven Shmanske (eds.). Oxford. Oxford University Press.

Lago, Ignacio, Carlos Lago-Peñas and Santiago Lago-Peñas. 2016. “Democracy and Football.” Social Science Quarterly 97: 1282-1294.

Llopis Goig, Ramón. 2006. “Clubes y selecciones nacionales de fútbol. La dimensión etnoterritorial del fútbol español.” Revista Internacional de Sociología 45: 3766.

Lublin, David. 2012. “Dispersing Authority or Deepening Divisions? Decentralization and Ethnoregional Party Success.” Journal of Politics 74: 1079-1093. 
Lublin, David. 2014. Minority Rules: Electoral Systems, Decentralization, and Ethnoregional Party Success. Oxford: Oxford University Press.

Martínez-Herrera, Enric. 2002. "From nation-building to building identification with political communities: Consequences of political decentralisation in Spain, the Basque Country, Catalonia and Galicia, 1978-2001.” European Journal of Political Research 41: 421-453.

Martínez-Vázquez, Jorge, Santiago Lago-Peñas and Agnese Sacchi. 2017. “The impact of fiscal decentralization: A survey.” Journal of Economic Surveys 31: 10951129.

O’Neill, Kathleen. 2003. "Decentralization as an electoral strategy." Comparative Political Studies 26: 1068-1091.

Putnam, Robert, D. 1995. "Bowling Alone: America's Declining Social Capital.” Journal of Democracy 6: 65-78.

Szymanski, Stefan. 2015. Money and Football. A Soccernomics Guide. New York: Nation Books.

Storn, Rasmus K. and Klaus Nielsen. 2012. "Soft budget constraints in professional football.” European Sport Management Quarterly 12: 183-201.

World Bank. 2000. Entering the 21st Century. Washington, DC: World Bank. 
Appendix

Table A1: Sample of countries in the pooled cross-sectional time-series analysis

\begin{tabular}{|c|c|c|c|c|c|}
\hline Country & Period & Country & Period & Country & Period \\
\hline Albania & $1960-2010$ & Austria & $1950-2010$ & Belgium & $1950-2010$ \\
\hline Bulgaria & $1990-2010$ & Croatia & $1990-2010$ & Cyprus & $1980-2010$ \\
\hline Czech Rep. & $1990-2010$ & Denmark & $1950-2010$ & Estonia & $1990-2010$ \\
\hline Finland & $1950-2010$ & France & $1950-2010$ & Germany & $1950-2010$ \\
\hline Greece & $1950-2010$ & Hungary & $1990-2010$ & Iceland & $1950-2010$ \\
\hline Ireland & $1950-2010$ & Italy & $1950-2010$ & Latvia & $1990-2010$ \\
\hline Lithuania & $1990-2010$ & Luxembourg & $1950-2010$ & Macedonia & $1990-2010$ \\
\hline Malta & $1960-2010$ & Netherlands & $1950-2010$ & Norway & $1950-2010$ \\
\hline Poland & $1990-2010$ & Portugal & $1980-2010$ & Romania & $1990-2010$ \\
\hline Serbia and & $2000-2010$ & Slovakia & $1990-2010$ & Slovenia & $1990-2010$ \\
Montenegro & & & & & \\
\hline Spain & $1980-2010$ & Sweden & $1950-2010$ & Switzerland & $1950-2010$ \\
\hline Turkey & $1960-2010$ & $\begin{array}{c}\text { United Kingdom } \\
\text { (England) }\end{array}$ & $1950-2010$ & & \\
\hline
\end{tabular}

